\section{Kinetic anaesthesia for laser surgery}

\begin{abstract}
Purpose Local anaesthetic is widely used in ophthalmic surgery and more recently in vitreoretinal surgery. Akinesia is a useful effect of local anaesthetic blocks, but there are situations where some residual globe movements are of benefit. We looked to see whether reducing the volume of anaesthetic solution used in a block could retain some kinesia while achieving good analgesia. Methods We compared two groups of patients undergoing panretinal photocoagulation (PRP) with an indirect laser. The control group received $5 \mathrm{ml}$ of anaesthetic solution in a single injection by a standard intraconal technique; a second group received a lower volume of solution by the same technique. We recorded the adequacy of anaesthesia and the amount of residual kinesia for the two groups. Differences between groups were analysed using the Student's $t$-test and $\chi^{2}$ tests.

Results The low-volume group received an average of $2.8 \mathrm{ml}$, compared to $5 \mathrm{ml}$ in the control group. There was no significant difference in the adequacy of analgesia achieved, however 16/18 (89\%: 95\% confidence intervals $(C I)=81.5-96.3 \%)$ of the low-volume group had good perioperative kinesia compared to just 3/21 (14\%: $95 \%$ $\mathrm{CI}=6.6-21.9 \%)$ of the controls $(P<0.001)$. Conclusions We have shown that low-volume intraconal blocks retain some perioperative kinesia without compromising their analgesic effect.

Eye (2005) 19, 1205-1207. doi:10.1038/sj.eye.6701745; published online 22 October 2004
\end{abstract}

Keywords: local anaesthesia; kinesia; indirect panretinal photocoagulation

\section{Introduction}

Local anaesthetics are widely used in ophthalmic surgery. Over the last 10 years anaesthesia for cataract surgery has moved from
FM Cuthbertson ${ }^{1}$, RSB Newsom ${ }^{1}$ and

AC Wainwright ${ }^{2}$

general, to peribulbar to topical anaesthesia. ${ }^{1-7}$ Vitreoretinal (VR) surgery has followed a similar pattern in many centres. Local anaesthesia has replaced general anaesthesia as it is well tolerated by patients and allows rapid postoperative recovery. ${ }^{8-16}$ Several local anaesthetic techniques for VR have been used and we have previously reported results using the anterior intraconal technique first described by Wong et al. ${ }^{17}$ Several authors comment that a potential problem with this technique was that total akinesia was difficult to achieve, which may make perioperative complications more likely. In our hands, however, we found that the intraconal block gave an akinetic block in the majority of cases. ${ }^{14}$ Experience in cataract surgery, however, has shown that full akinesia may not be necessary so long as the patients have good analgesia, and for some procedures a degree of movement of the globe can be useful.

In this study, we assessed the effect of reducing the volume of local anaesthetic used on the perioperative anaesthesia and globe kinesia, attempting to produce a block that gave good anaesthesia with some residual kinesia.

\section{Methods}

We undertook a prospective audit on all patients undergoing frequency doubled, yttrium aluminium garnet (FDYAG) laser panretinal photocoagulation (PRP) with an indirect laser under local anaesthetic between 3rd September 2003 and 9th January 2004. All patients received a peribulbar block with a combination of lidocaine (lignocaine), bupivacaine, and hyaluronidase at a volume between 2 and $4 \mathrm{ml}$. These patients were compared with a control group, also having PRP, who received standard $5 \mathrm{ml}$ intraconal blocks from the same anaesthetist over the same time period. All blocks consisted of a single inferotemporal injection.

The patient's age, the volume of local anaesthetic used, the pain rating of the injection
${ }^{1}$ Southampton Eye Unit, Southampton, UK

${ }^{2}$ Shackleton Department of Anaesthesia, UK

Correspondence:

FM Cuthbertson,

Department of

Opthalmology,

Southampton University

Hospitals, NHS Trust,

Southampton General

Hospital,

Tremona Road,

Southampton SO16 6YD, UK

Tel: + 442380794758 ;

Fax: +44 2380794120 .

E-mail: fcuthbertson@

hotmail.com

Received: 9 May 2004 Accepted: 2 September 2004

Published online:

22 October 2004

Proprietary interests: None Research funding: None 
itself (scale 1-4: 1 being no pain felt, 2 no comment, 3 moderate discomfort, and 4 severe pain), the pain rating perioperatively (scale 1-4: 1 no pain, 2 mild, 3 moderate, and 4 severe), the need for any top-up injection and the use of sedation was recorded. We also graded the amount of globe kinesia perioperatively (scale 1-4: 1 no movement or flicker, 2 some movement, 3 moderate movement, and 4 full movement) and the direction of any residual movement.

\section{Statistical methods}

The age of the patient and the volume of the local anaesthetic used were compared using the Student's $t$-test. The proportion of patients experiencing perioperative pain and who had residual kinesia are reported as percentages with $95 \%$ confidence intervals (CI), and were compared using the $\chi^{2}$ test.

\section{Results}

A total of 18 patients undergoing PRP received the lowvolume peribulbar block, compared to 21 controls who received the standard block for the same procedure. The groups were of similar age, with a mean age of 57.4 years (range 28-84) in the low-volume group and 52.7 years (range 32-84) in the control group. The average volume of local anaesthetic injection (Figure 1) in the low-volume group was $2.8 \mathrm{ml}$ compared to $5 \mathrm{ml}$ in the control group $(P<0.001)$.

In terms of the anaesthesia achieved, 1/18 (5.6\%: 95\% CI) $0.2-11.0 \%$ ) in the low-volume group had poor anaesthesia, compared to $0 / 21(95 \%$ CI $0-9.4 \%)$ in the control group $(P=0.9) .16 / 18$ of low-volume patients (89\%: 95\% CI 81.5-96.3\%) had good kinesia (scoring 2 or above), compared to $3 / 21$ of controls (14\%: $95 \% \mathrm{CI}$ $6.6-21.9 \%)(P<0.001)$ (Figure 2$)$. The direction of the residual movement varied, but $11 / 16$ patients had movement in all directions.

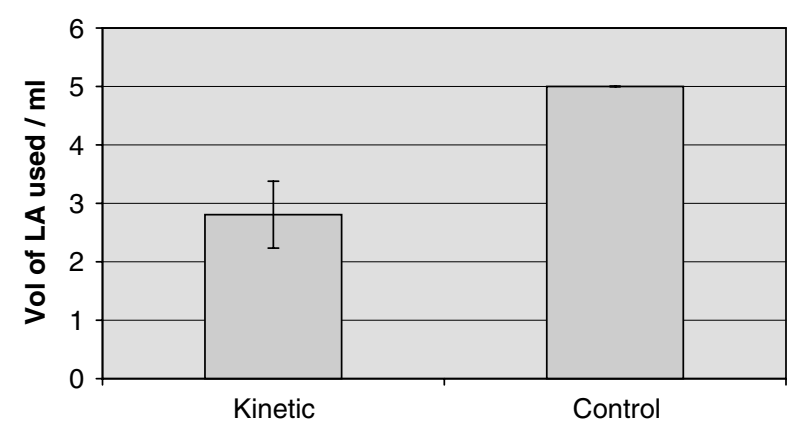

Figure 1 Volume of local anaesthetic used.

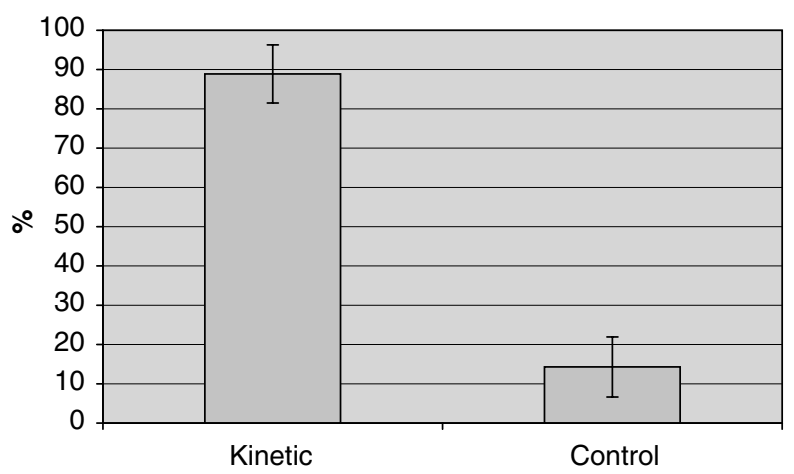

Figure 2 Proportion of patients with useful kinesia.

\section{Discussion}

Anaesthesia for cataract surgery has developed from general anaesthesia (GA) to local anaesthesia (LA), and in many centres to topical anaesthesia. ${ }^{1-7}$ The standard LA block giving good analgesia combined with total akinesia has been superceded in many centres by topical anaesthesia, as a cooperative patient can provide acceptable surgical conditions with rapid patient recovery.

In the past, LA for vitreoretinal surgery has been less frequently used; however is becoming more popular both in the UK and abroad. A variety of methods have been described. ${ }^{8-17}$ Advantages of LA over GA include more rapid patient recovery; however also there are some procedures where having an awake patient who is able to cooperate and follow instructions can be helpful. In PRP treatment, the retention of motility such that the patient is able to move the eye around on request leads to an easier view of the peripheral retina with less need for indenting, less conjunctival trauma, and more complete peripheral treatment. The reduced amount of trauma on the eye results in less postoperative pain and inflammation, and hence a faster recovery.

There has been some suggestion in the literature that altering the volume of local anaesthetic used may result in varying degrees of kinesia. Ortiz et $a l^{18}$ looked at peribulbar blocks in patients undergoing cataract surgery, and compared volumes of 5 and $9 \mathrm{ml}$ bupivacaine, noting a significantly better motor block in the latter group.

We used a slightly different technique with $5 \mathrm{ml}$ of a mixture of lidocaine, bupivacaine, and hyaluronidase compared to smaller volumes when used in a singleinjection peribulbar block. Our results support the idea that using a lower volume of anaesthetic solution maintains kinesia while retaining good analgesia. We did not have sufficient numbers of patients to comment on the relative effects of different volumes of anaesthetic within the range tried, although the initial impression is 
that smaller volumes may be associated with more kinesia.

As suggested earlier, a 'successful' local anaesthetic block can be thought of in a number of ways, but a reasonable definition would be one that allows comfort and pain relief for the patient while creating optimal operating conditions for the surgeon. For our patients undergoing this particular procedure, a degree of residual kinesia following the local anaesthetic block was achievable without loss of any analgesia by using a lower volume of anaesthetic during the block than has been our previous standard practice.

\section{References}

1 Eke T, Thompson JR. The National Survey of Local Anaesthesia for Ocular Surgery. 1. Survey of methodology and current practice. Eye 1999; 13(2): 189-195.

2 Davis II DB, Mandel M. Posterior peribulbar anesthesia, an alternative to retrobulbar anesthesia. J Cataract Refract Surg 1986; 12: 182-184.

3 Friedmann DS, Bass EB, Lubomski LH, Fleisher LA, Kempen JH, Magaziner J et al. Synthesis of the literature on the effectiveness of regional anaesthesia for cataract surgery. Ophthalmology 2001; 108(3): 519-529.

4 Loots JH, Koorts AS, Venter JA. Peribulbar anaesthesia. A prospective statistical analysis of the efficacy and predictability of bupivacaine and a lignocaine/bupivacaine mixture. J Cataract Refract Surg 1993; 19(1): 72-76.

5 Oji E, Oji A. Bupivacaine and lignocaine for ophthalmic surgery. Br J Ophthalmol 1987; 71(1): 66-68.

6 Budd J, Hardwick M, Barber K, Prosser J. A single centre study of 1000 consecutive peribulbar blocks. Eye 2001; 15(4): 464-468.
7 Eke T, Thompson JR. The National Survey of Local Anaesthesia for Ocular Surgery. II. Safety profiles of local anaesthesia techniques. Eye 1999; 13(2): 196-204.

8 Demediuk O, Dhaliwal R, Papworth D, Devenyi R, Wong D. A comparison of peribulbar and retrobulbar anesthesia for vitreoretinal surgical procedures. Arch Ophthalmol 1995; 113(7): 908-913.

9 Benedetti S, Agostini A. Peribulbar anesthesia for vitreoretinal surgery. Retina 1994; 14: 277-280.

10 Rao GP, Wong D, Groenwald C, McGalliard JN, Jones A, Ridges PJG. Local anaesthesia for vitreoretinal surgery: a case-control study of 200 cases. Eye 1998; 12: 407.

11 Kwok A, Van Newkirk M, Lam D, Fan D. Subtenons anesthesia in vitreoretinal surgery. Retina 1999; 19: 291-296.

12 Yepez J, Yepez J, Arevalo J. Topical anesthesia in posterior vitrectomy. Retina 2000; 20: 41-45.

13 Sharma T, Gopal L, Parikh S, Shanmugam MP, Badrinath SS, Mukesh BN. Parabulbar anaesthesia for primary vitroretinal surgery. Ophthalmology 1997; 104(3): 425-428.

14 Newsom RSB, Wainwright AC, Canning CR. Local anaesthesia for 1221 vitreoretinal procedures. $\mathrm{Br} J$ Ophthalmol 2001; 85: 225-227.

15 Calenda E, Olle P, Muraine M, Brasseur G. Peribulbar anaesthesia and sub-Tenon injection for vitreoretinal surgery: 300 cases. Anaesthesiology 2000; 92(5): 1278-1285.

16 Mutsch A, Hartwig S, Schenkel A, Schenkel C, Hasenfratz G. Vitreoretinal operations with local anaesthesia. Ophthalmology 1996; 93(6): 719-723.

17 Wong DH, Koehrer E, Sutton HF, Merrick P. A modified retrobulbar block for eye surgery. Can J Anaesth 1993; 40(6): 547-553.

18 Ortiz M, Blanco D, Serra J, Vidal F. Peribulbar anaesthesia: the role of local anaesthetic volumes and thiomucase in motor block and intraocular pressure. Eur J Ophthamol 1995; 12(6): 603-607. 